\title{
The effect of acute tryptophan depletion on the BOLD response during performance monitoring and response inhibition in healthy male volunteers.
}

Citation for published version (APA):

Evers, E. A., van der Veen, F. M., van Deursen, J. A., Schmitt, J. A., Deutz, N. E., \& Jolles, J. (2006). The effect of acute tryptophan depletion on the BOLD response during performance monitoring and response inhibition in healthy male volunteers. Psychopharmacology, 187(2), 200-208.

https://doi.org/10.1007/s00213-006-0411-6

Document status and date:

Published: 01/01/2006

DOI:

10.1007/s00213-006-0411-6

Document Version:

Publisher's PDF, also known as Version of record

Please check the document version of this publication:

- A submitted manuscript is the version of the article upon submission and before peer-review. There can be important differences between the submitted version and the official published version of record.

People interested in the research are advised to contact the author for the final version of the publication, or visit the DOI to the publisher's website.

- The final author version and the galley proof are versions of the publication after peer review.

- The final published version features the final layout of the paper including the volume, issue and page numbers.

Link to publication

\footnotetext{
General rights rights.

- You may freely distribute the URL identifying the publication in the public portal. please follow below link for the End User Agreement:

www.umlib.nl/taverne-license

Take down policy

If you believe that this document breaches copyright please contact us at:

repository@maastrichtuniversity.nl

providing details and we will investigate your claim.
}

Copyright and moral rights for the publications made accessible in the public portal are retained by the authors and/or other copyright owners and it is a condition of accessing publications that users recognise and abide by the legal requirements associated with these

- Users may download and print one copy of any publication from the public portal for the purpose of private study or research.

- You may not further distribute the material or use it for any profit-making activity or commercial gain

If the publication is distributed under the terms of Article $25 \mathrm{fa}$ of the Dutch Copyright Act, indicated by the "Taverne" license above, 


\title{
The effect of acute tryptophan depletion on the BOLD response during performance monitoring and response inhibition in healthy male volunteers
}

\author{
Elisabeth A. T. Evers • Frederik M. van der Veen • \\ Jeroen A. van Deursen - Jeroen A. J. Schmitt • \\ Nicolaas E. P. Deutz • Jelle Jolles
}

Received: 27 January 2006 / Accepted: 10 April 2006 /Published online: 19 May 2006

(C) Springer-Verlag 2006

\begin{abstract}
Rationale Serotonin (5-HT) was implicated in both clinical and experimental studies in flexible, goal-directed behavior. However, the way in which 5-HT manipulations affect brain activation patterns underlying different subprocesses of cognitive flexibility remains largely unknown.

Objectives The aim of this study was to investigate the effect of a transient lowering of 5-HT on brain activation during performance monitoring and response inhibition. Materials and methods We used acute tryptophan depletion (ATD), a well-known method to reduce central 5-HT, to investigate the effect of a transient lowering of 5-HT on the blood-oxygen-level dependent (BOLD) response in an event-related functional MRI study. Thirteen healthy male volunteers performed a modified Go/NoGo task in a counterbalanced, placebo-controlled, within-subject design. Results ATD significantly lowered plasma tryptophan but did not affect mood and cognitive performance. ATD decreased the BOLD response in the dorsomedial prefrontal cortex (BA 8) during performance monitoring. ATD did not
\end{abstract}

E. A. Evers $(\bowtie) \cdot J$. A. van Deursen · J. Jolles

Department of Psychiatry and Neuropsychology (DRT 10),

Brain and Behavior Institute, Maastricht University,

P.O. Box 616, 6200 MD Maastricht, Netherlands

e-mail: 1.evers@np.unimaas.nl

F. M. van der Veen

Department of Psychiatry, Erasmus Medical Centre,

Rotterdam, Netherlands

\section{J. A. Schmitt}

Department Nutrition and Health, Nestlé Research Centre,

Lausanne, Switzerland

N. E. Deutz

Department of Surgery, Maastricht University,

Maastricht, Netherlands affect the BOLD response during response inhibition. Conclusions This study provides more evidence for the suggested role of 5-HT in performance monitoring. Because ATD studies have revealed inconsistent effects of ATD on performance and on brain activation, it was suggested that gender and personality traits are important variables to take into account for future research.

Keywords Serotonin - Acute tryptophan depletion . Performance monitoring $\cdot$ Response inhibition .

Neuroimaging

\section{Introduction}

Previous animal and human research showed that serotonin (5-HT) is implicated in cognitive flexibility tasks (for review, see Robbins 2005). Cognitive flexibility is the ability to quickly adapt performance to task-related changes. It was shown that acute tryptophan depletion (ATD), a method to temporarily reduce brain 5-HT levels, impaired performance during reversal learning (Park et al. 1994; Rogers et al. 1999) and decision making (Rogers et al. 1999, 2003) in healthy volunteers. In contrast, other studies did not find an effect of reduced 5-HT on cognitive flexibility (Anderson et al. 2003; Talbot et al. 2005). Several cognitive processes are important for cognitive flexibility, for example performance monitoring and response inhibition. It remains unclear how these processes are affected by a transient lowering of 5-HT. The present study investigated the effect of low 5-HT on performance and brain activation during performance monitoring and response inhibition.

Previous studies showed that low 5-HT impaired performance monitoring and response inhibition. For example, patients suffering from unipolar depression, a 
disorder associated with disturbed 5-HT functioning (for review, see Risch and Nemeroff 1992), showed an impaired response to negative feedback. Two previous studies (Beats et al. 1996; Elliott et al. 1997) reported that depressed patients fail to improve performance after perceived failure, which suggests cognitive inflexibility. Murphy et al. (2003) showed impaired ability to maintain a response set in the face of misleading negative feedback in depressed patients, which indicates an increased tendency to change response strategy. Fallgatter et al. (2004) investigated the modulation of the brain electrical response to error processing as a function of allelic variation of 5-HT transporter function. They showed significantly higher amplitude of the errorrelated negativity, indicating an enhanced responsiveness of the anterior cingulate cortex (ACC) during error processing, when participants carried a short allele of the 5-HT transporter. Animal studies showed that the administration of the neurotoxin 5,7-dihydroxytryptamine, depleting brain 5-HT, resulted in poorer response inhibition on a Go/NoGo task (Harrison et al. 1999) and increased impulsivity in a five-choice, serial reaction time task (Harrison et al. 1997; Winstanley et al. 2004) in rats. Furthermore, depressed patients showed disturbed response inhibition on a $\mathrm{Go} /$ NoGo task (Kaiser et al. 2003). In contrast to the suggested importance of 5-HT for response inhibition, no effects of ATD were found on response inhibition performance in healthy volunteers (Clark et al. 2005; Cools et al. 2005a; Crean et al. 2002; Le Marquand et al. 1998, 1999; Rubia et al. 2005). Only one study that we are aware of showed an increase in impulsive response style after ATD (Walderhaug et al. 2002).

Three previous functional MRI (fMRI) studies investigated the effect of ATD on brain activation while healthy volunteers performed a cognitive task. Horacek et al. (2005) showed that ATD increased activation in the bilateral medial, inferior, and superior prefrontal cortex (PFC) and in the ACC during the interference condition of a Stroop task. Rubia et al. (2005) investigated the effect of ATD on brain activation during response inhibition using a standard Go/NoGo task. ATD increased the bloodoxygen-level dependent (BOLD) response in the superior and medial temporal cortices, but decreased the BOLD response in the right inferior $\mathrm{PFC}$ during response inhibition. Finally, Evers et al. (2005) showed that ATD increased the BOLD response in the dorsomedial PFC (dmPFC) during probabilistic reversal learning. In addition, two positron-emission tomography studies have examined the effect of ATD on the activation of a resting brain in depressed patients (Bremner et al. 1997; Smith et al. 1999; Morris et al. 1999). A diverse range of areas was affected by ATD including the orbitofrontal cortex, the ACC, the caudate, raphe and habenula nucleus, the thalamus, and the dorsolateral PFC.
The aim of the current study was to investigate the effect of a transient lowering of 5-HT, by means of ATD, on brain activation patterns underlying performance monitoring and response inhibition. ATD is a well-established, noninvasive method that adequately reduces the release and synthesis of brain 5-HT in humans (Biggio et al. 1974; Fadda 2000; Williams et al. 1999; Nishizawa et al. 1997). In the present study, healthy male volunteers performed a modified Go/NoGo task in which performance feedback was given after each response, in an event-related fMRI design. In accordance with above-mentioned studies that showed that ATD did not affect response inhibition in healthy volunteers, we hypothesized that performance would not be affected by ATD. Furthermore, we hypothesized that ATD affects the BOLD response in dorsomedial frontal regions (based on Evers et al. 2005; Fallgatter et al. 2004) during performance monitoring and in the right inferior frontal cortex (based on Rubia et al. 2005) during response inhibition.

\section{Materials and methods}

\section{Participants}

Seventeen healthy, right-handed male volunteers were included in this study, which was approved by the Medical Ethics Committee of the Maastricht University Hospital. Data of four volunteers could not be used for analysis due to technical problems. The remaining participants $(n=13)$ were, on average, 23 years old $(\mathrm{SD}=1.8)$ and were mostly pregraduate students. Participants were recruited by local advertisements and were not suffering from significant past or present physical or psychiatric illnesses, which was checked by a medical health questionnaire. They received no medication at the moment of inclusion and were screened for MRI contraindications. This study was carried out in accordance with the declaration of Helsinki and all volunteers gave written informed consent before their inclusion in the study. The participants were paid 75 euros.

\section{Experimental design}

Participants were scanned at the Academic Hospital Maastricht on two separate test days, that is, an experimental and a placebo test session counterbalanced according to a double-blind crossover design. Participants arrived in the afternoon, after they have fasted overnight and eaten a lowprotein breakfast at home. They were given a tryptophandepleted (TRP-) or a balanced (BAL) amino acid (AA) mixture, followed by a 5 -h break to ensure stable and low plasma TRP levels (Riedel et al. 1999). In this break, only 
low protein food was eaten. In the evening (between 5 and 8.30 p.m.) the participants were scanned while performing two blocks of the Go/NoGo task, each lasting about $5.5 \mathrm{~min}$. The participants also performed a memory task, but the results of this part of the experiment will be presented elsewhere (van der Veen et al. 2006). The order of testing was as follows: the first $\mathrm{Go} / \mathrm{NoGo}$ block (5.5 min), the encoding block of the memory task $(7.5 \mathrm{~min})$, the second Go/NoGo block (5.5 min), the structural scan (10 $\mathrm{min}$ ), and the recognition block of the memory task (11 min). Participants were trained in a dummy scanner on a separate day before the first test sessions to make sure that they were comfortable in the scanner and they could perform the task well.

\section{The Go/NoGo task}

The present study used a modified version of the Go/NoGo task described by Garavan et al. (1999). The task was programmed in E-Prime V1.0 (Psychology Software Tools 2002). A stream of letters (yellow on a black background) was presented, showing one letter every $500 \mathrm{~ms}$ with a 0-ms interstimulus interval. The participants' task was to respond to an X preceded by a Y or a Y preceded by an X (Go trials) by pressing a button on a response box with their right index finger. Participants had to refrain from responding when an $\mathrm{X}$ was preceded by an $\mathrm{X}$ or a $\mathrm{Y}$ by a $\mathrm{Y}$ (NoGo or inhibition trials). Feedback, which started $500 \mathrm{~ms}$ after the presentation of a letter (fixed delay) and was presented for $500 \mathrm{~ms}$, was added to the original task design to motivate the participants. Correct Go and NoGo trials were followed by a green square (positive feedback); incorrect responses were followed by a red square (negative feedback). Negative feedback was given after a response to an inhibition trial, a response to a letter other than an $\mathrm{X}$ or a $\mathrm{Y}$, no response to a Go trial, or a response was given after a time limit of $500 \mathrm{~ms}$. This time limit was added to assure fast response. The response had to be made when the stimulus was still on the screen. Feedback was given after the stimulus presentation. A NoGo trial was presented every $25 \mathrm{~s}$ on average and a Go trial every $4 \mathrm{~s}$ on average. In each test session, 1,000 stimuli were presented, of which 25 were NoGo and 150 were Go trials, divided into two blocks each lasting about $5 \mathrm{~min}$. Four different versions were used in a randomized order. Participants were trained before the actual testing. In the first training task, no NoGo trials (400 stimuli, of which 120 were Go trials), and in the second training task, seven NoGo trials (350 stimuli, of which 55 were Go trials and 7 were NoGo trials) were presented in addition to the Go trials. The experimental task contained three events of interest: correctly executed Go trials followed by positive feedback (Gos) correctly inhibited NoGo trials followed by positive feedback (NoGos) and errors on Go or NoGo trials followed by negative feedback (Errors).

Performance data

The following measures were used: the number of correct Gos, the number of correct NoGos, the mean reaction time (RT) on Go trials after a correct response (a measure for general responding speed), after an incorrect Go, and after an incorrect NoGo trial, (measures for the behavioral adaptation after a response error). The effect of ATD on the number of correct Gos, the number of correct NoGos, and the RT measures was analyzed (SPSS version 11.5 for Windows) using repeated measures ANOVA with Treatment (BAL or TRP-) as a within subject variable and Order (TRP- or BAL mixture first) as a between subject variable. The differences between the RT measures within the BAL and TRP- conditions were analyzed using paired-samples $t$ tests.

Amino acid mixtures

The TRP-deficient (TRP-) amino acid (AA) mixture contained $75 \mathrm{~g}$ of AAs with the amounts of each specific AA according to the following proportions: $4.1 \mathrm{~g} \mathrm{~L}$-alanine, $2.4 \mathrm{~g}$ L-glycine, $2.4 \mathrm{~g}$ L-histidine, $6.0 \mathrm{~g}$ L-isoleucine, $10.1 \mathrm{~g}$ L-leucine, $6.7 \mathrm{~g}$ L-lysine, $4.3 \mathrm{~g}$ L-phenylalanine, $9.2 \mathrm{~g}$ L-proline, $5.2 \mathrm{~g}$ L-serine, $4.9 \mathrm{~g}$ L-threonine, $5.2 \mathrm{~g}$ L-tyrosine, $6.7 \mathrm{~g}$ L-valine, $3.7 \mathrm{~g}$ L-arginine, $2.0 \mathrm{~g}$ L-cysteine, and $2.3 \mathrm{~g}$ L-methionine. The nutritionally balanced (BAL) mixture contained the same amount of these AAs, plus $3.0 \mathrm{~g}$ TRP. The mixtures were prepared with $200 \mathrm{ml}$ tap water.

\section{Biochemical measures}

Blood samples $(10 \mathrm{ml})$ were taken immediately before ingestion of the AA mixture and just before the scanning session, about $41 / 2 \mathrm{~h}$ after administration, to determine the plasma TRP level and the TRP/ $\mathrm{LLNAA}$ ratio. The TRP/ LLNAA ratio was calculated as follows: (TRP) / (tyrosine + leucine + phenylalanine + isoleucine + valine $)$. The blood samples were immediately centrifuged at $4{ }^{\circ} \mathrm{C}$ (10 $\mathrm{min}, 4,500 \mathrm{rpm}$ ). One hundred microliters aliquot of plasma was mixed with $8 \mathrm{mg}$ sulfa salicylic acid and frozen at $-80^{\circ} \mathrm{C}$ until determination of the AAs by high-performance liquid chromatography (van Eijk et al. 1993). Total plasma TRP level and the TRP/ $L$ LNAA ratio were analyzed using repeated measures ANOVA with Time (t0 and t5) and Treatment (BAL or TRP-) as within-subject variables and Order (TRP- or BAL mixture first) as between subject variable. Paired-sample $t$ tests were used to compare baseline measurements. 
Questionnaires

\section{Mood}

A visual analog version of the Profile of Mood States (POMS) was used to assess mood (McNair et al. 1988). This questionnaire consists of 32 bipolar sets of adjectives, which measure five mood dimensions: anger, depression, fatigue, tension, and vigor. The items were scored on a 10 -point scale. When the participants felt as they normally would, they were asked to mark the middle of the line (score 5).

\section{Adverse effect}

Adverse effects, 31 items, were registered and scored on a 4-point scale from "no complaint at all" (0) to "severe complaint" (4). A total score was calculated by adding the scores on the individual items.

The effect of ATD on mood and adverse effects was analyzed using repeated measures ANOVA with Time (t0 and $\mathrm{t5}$ ) and Treatment (BAL or TRP-) as within-subject variables and Order (TRP- or BAL mixture first) as between subject variable.

Image acquisition

Participants were scanned in a $1.5 \mathrm{~T}$ Philips scanner at the Academic Hospital Maastricht. T2*-weighted gradient echo planer images $(\mathrm{TE}=27 \mathrm{~ms})$ were acquired with BOLD contrast. A whole brain acquisition consisted of 24 slices (slice thickness $5 \mathrm{~mm}$; TR $1.75 \mathrm{~s}$; voxel size before normalization was $3.5 \times 3.5 \times 5 \mathrm{~mm}$ and after normalization $2 \times 2 \times 2 \mathrm{~mm}$; no slice gap; matrix size $64 \times 64 \times 24$; oblique transversal orientation; flip angle $90^{\circ}$ ), and 190 volumes were acquired for each $\mathrm{Go} / \mathrm{NoGo}$ block. The stimulus presentation and the scanning were synchronized at the beginning of each run. High-resolution T1-weighted images for anatomical localization were made of each participant (voxel size $1 \times 1 \times 1 \mathrm{~mm}$ ).

Image analysis

SPM2 (Statistical Parametric Mapping; Wellcome Department of Cognitive Neurology, London, UK) was used for data processing. Preprocessing procedures included slice acquisition time correction and within-subject realignment. Images from session 2 were then coregistered to the mean image from session 1 and thereafter spatially normalized to the standard Montreal Neurological Institute (MNI) structural template (SPM2). Finally, the images were spatially smoothed using a Gaussian $(8 \mathrm{~mm}$ full-width at half maximum) kernel and high pass filtered.
A canonical hemodynamic response was used as a covariate in a general linear model, and a parametric estimate was generated for each voxel for Gos, NoGos, and Errors. Individual contrast images were taken to a second level analysis (one sample $t$ test), in which $t$ values were calculated for each voxel treating intersubject variability as a random effect. The hemodynamic response function was modeled to the onset of the response.

The following contrasts were calculated for the BAL and the TRP- condition together to assess task effects (whole brain analysis; $P_{\text {cluster-corrected }}<0.05$ ):

1. Performance monitoring Errors minus Correct (NoGos+Gos) (contrast 1), (contrast weights-2 1 1)

2. Response inhibition NoGos minus Gos (contrast 2)

The following contrasts were calculated to assess the effect of ATD:

3. Effect of ATD on performance monitoring Contrast 1 in the TRP- condition compared with contrast 1 in the BAL condition (contrast 3)

4. Effect of ATD on response inhibition Contrast 2 in the TRP-condition compared with contrast 2 in the BAL condition (contrast 4)

5. As a control condition, effect of ATD on overall activation All event types (Gos, NoGos, and Errors) in the TRP- condition compared with all event types in the BAL condition (contrast 5)

The effect of ATD was analyzed using whole brain analysis $\left(P_{\text {cluster-corrected }}<0.05\right.$ and extent threshold of $>20$ voxels). In a previous study, we showed that ATD increased the BOLD response in the $\mathrm{dmPFC}$ region after the last reversal error in a probabilistic reversal learning task (Evers et al. 2005). This region was used as a region of interest (ROI) (SPM, small volume correction; 10-mm sphere around the center coordinated MNI: $x=9, y=39, z=48$ ) for the effect of ATD on brain activation during performance monitoring. The Talaraich Daemon was used to label the coordinates of the anatomical regions (http://ric.uthscsa.edu/TDapplet/).

\section{Results}

Performance and fMRI data were complete for 13 participants; eight participants started in the BAL condition and five started in the TRP- condition. Participants were scanned $5 \mathrm{~h}$ on average after ingesting the AA mixture.

Imaging

No main task effect was found for performance monitoring (contrast 1; BAL and TRP-data together). However, in the 
Table 1 Brain areas related to response inhibition; NoGo trials compared with Go trials for the BAL and the TRP- condition together

\begin{tabular}{|c|c|c|c|c|c|}
\hline & MNI coordinates & $T$ value & $P$ value & Number of voxels & Brodmann area \\
\hline \multirow[t]{3}{*}{ Right inferior parietal/supramarginal cluster } & $(48,-46,36)$ & 14.39 & \multirow[t]{3}{*}{0.000} & \multirow[t]{3}{*}{1,666} & 40 \\
\hline & $(52,-52,42)$ & 12.09 & & & 40 \\
\hline & $(52,-54,30)$ & 10.01 & & & 40 \\
\hline \multirow[t]{3}{*}{ Right middle/superior frontal and precentral cluster } & $(48,34,22)$ & 10.06 & \multirow[t]{3}{*}{0.000} & \multirow[t]{3}{*}{2,357} & 46 \\
\hline & $(30,52,24)$ & 8.44 & & & 10 \\
\hline & $(52,10,6)$ & 7.85 & & & 44 \\
\hline \multirow[t]{3}{*}{ Right medial/superior frontal cluster } & $(2,26,42)$ & 8.10 & \multirow[t]{3}{*}{0.000} & \multirow[t]{3}{*}{959} & 8 \\
\hline & $(0,34,40)$ & 7.92 & & & 8 \\
\hline & $(20,18,58)$ & 7.97 & & & 6 \\
\hline \multirow[t]{3}{*}{ Left superior/inferior parietal and precuneus cluster } & $(-34,-60,54)$ & 7.90 & \multirow[t]{3}{*}{0.000} & \multirow[t]{3}{*}{845} & 7 \\
\hline & $(-58,-50,38)$ & 6.28 & & & 40 \\
\hline & $(-28,-72,50)$ & 5.97 & & & 7 \\
\hline \multirow[t]{3}{*}{ Left inferior/middle frontal cluster } & $(-30,26,-6)$ & 7.12 & \multirow[t]{3}{*}{0.000} & \multirow[t]{3}{*}{639} & 47 \\
\hline & $(-48,10,42)$ & 5.86 & & & 8 \\
\hline & $(-40,30,28)$ & 5.36 & & & 9 \\
\hline \multirow[t]{2}{*}{ Right middle temporal cluster } & $(60,-36,-6)$ & 6.06 & \multirow[t]{2}{*}{0.045} & \multirow[t]{2}{*}{122} & 21 \\
\hline & $(60,-26,-12)$ & 5.89 & & & 21 \\
\hline
\end{tabular}

Only areas for which $P_{\text {corrected-cluster }}<0.05$ in whole brain analysis are shown

BAL condition performance monitoring was associated with a significantly increased BOLD response in the ACC (MNI, $x=6, y=26, z=40 ; T=5.62 ; P_{\text {cluster-corrected }}=0.037 ; 156$ voxels; BA 32). Response inhibition (contrast 2; BAL and TRP- data together) was associated with a significantly increased BOLD response in a right inferior parietal/ supramarginal cluster (BA 40), a right middle/superior frontal and precentral cluster (BA 10/44/46), a right medial/ superior frontal cluster (BA 6/8), a left superior/inferior parietal and precuneus cluster (BA 7/40), a left inferior/ middle frontal cluster (BA 8/9/47), and a right middle temporal cluster (BA 21) (see Table 1).

ATD decreased the BOLD response in the $\mathrm{dmPFC}$ cortex (ROI analysis; MNI, $x=4, y=44, \mathrm{z}=40 ; \quad T=4.98$;

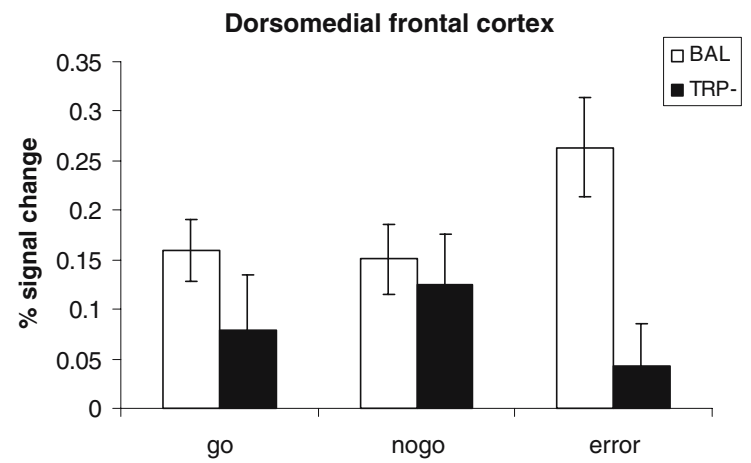

Fig. 1 Percent signal change in the BAL and the TRP- condition for the dorsomedial prefrontal activation cluster. Percent signal changes were calculated with Marsbar (http://marsbar.sourceforge.net/). The presented percentage signal change is the mean value for the two blocks per condition
$P_{\text {cluster-corrected }}=0.037$; seven voxels; BA 8) during performance monitoring (contrast 3 ). No effect of ATD was found on brain activation associated with response inhibition (contrast 4). Percent signal change for both the BAL and the TRP- condition in the dmPFC activation cluster is shown in Fig. 1.

Because no effect of ATD on overall activation was found (contrast 5), the effect of ATD in the dmPFC was not confounded by overall effects of ATD. Talbot and Cooper (2006) showed that individual changes in depressed mood after ATD without an overall mood effect affected the BOLD response in the subgenual ACC and associated regions. Therefore, we conducted a post hoc analysis to examine whether the effect of ATD on the BOLD response in the dmPFC is confounded by mood changes. Post hoc ANCOVA analysis showed that the effect of ATD on the response in the dmPFC was not confounded by mood. After correction for the delta depression score [score on the depression subscale of the POMS at TRP- $(\mathrm{t} 5-\mathrm{t} 0)$ minus BAL (t5-t0)] ATD decreased the BOLD response in the dmPFC (ROI analysis; MNI, $x=4, y=44, z=40 ; T=4.84$; $P_{\text {cluster-corrected }}=0.048$; four voxels; BA 8 ). In addition, the effect of ATD during performance monitoring was not confounded by the fact that eight participants started in the BAL and five participants in the TRP- condition. Repeated measures analysis with Treatment as within subject factor and Order as between subject factor showed that the percent signal change extracted from the dmPFC (two times Error minus Go and minus NoGo percentage signal change) was not affected by Order (Treatment $\times$ Order interaction: $F(1,11)=3.6 ; p=0.08)$. 
Table 2 Performance data for the Go/NoGo task: means with standard errors of the mean and the total number of events for reaction times

\begin{tabular}{lll}
\hline Events & BAL & TRP- \\
\hline Percentage correct NoGos & $68(2)$ & $72(1)$ \\
Percentage correct Gos & $91(3)$ & $93(3)$ \\
$\begin{array}{l}\text { Mean reaction time (ms) on a correct Go } \\
\quad \text { after a correct response }\end{array}$ & $370(1)$ & $369(1)$ \\
& $n=1,738$ & $n=1,839$ \\
$\begin{array}{l}\text { Mean reaction time (ms) on a correct Go } \\
\quad 375(5)\end{array}$ & $373(6)$ \\
$\quad$ & $n=92$ & $n=75$ \\
Mean reaction time (ms) on a correct Go & $384(4)$ & $379(6)$ \\
$\quad$ after an error on a Go trail (misses) & $n=141$ & $n=110$ \\
\hline
\end{tabular}

Biochemical results

Twelve samples from the BAL condition and 13 samples from the TRP-condition were available for analysis. No difference in total plasma TRP (mean/SEM, BAL 47.6/1.5; TRP- 47.4/1.3) and the TRP/ $\Sigma$ LNAA ratio (BAL 0.10/0.01; TRP $0.10 / 0.00$ ) at baseline ( $t 0)$ was found between the BAL and the TRP- condition. In the TRP- condition, total plasma TRP (19.4/2.5) and the TRP/ $\Sigma L N A A$ ratio $(0.02 / 0.00)$ were significantly lowered [Treatment $\times$ Time interaction for total plasma TRP, $F(1,10)=44.7, p=0.000$; Treatment $\times$ Time interaction for the ratio, $F(1,10)=96.9, p=0.000] 5 \mathrm{~h}$ after the AA mixture. Total plasma TRP dropped by $59 \%$ and the TRP/ $\Sigma L N A A$ ratio by $77 \%$ after ingesting the TRPmixture. In the BAL condition levels of total plasma TRP $(108.5 / 12.2)$ were significantly increased $(\mathrm{t} 11=-4.9$; $p<0.01)$, but the TRP/ $\Sigma$ LNAA ratio $(0.11 / 0.01)$ was not changed $(\mathrm{T} 11=-1.15 ; p>0.05) 5 \mathrm{~h}$ after the AA mixture. Total plasma TRP increased by $128 \%$ and the TRP/ $\Sigma$ LNAA ratio increased by $15 \%$ after the BAL mixture.

\section{Performance}

Performance data $(n=13)$ is shown in Table 2. No effect of ATD was found on the number of correct Gos and correct NoGos. Participants successfully completed, on average, 18.6 correct NoGos $(\mathrm{SE}=1.2)$ in the TRP- condition and 17.1 correct NoGos $(\mathrm{SE}=1.5)$ in the $\mathrm{BAL}$ condition. Participants made on average 17 Errors $(\mathrm{SE}=3.5)$ in the TRP- condition and 21 Errors $(\mathrm{SE}=4.3)$ in the BAL condition. In the BAL and in the TRP- condition, participants reacted faster on a correct Go trial after a correct response than on a correct Go trial after an incorrect Go trial (BAL, $T=-4.77, p=0.000$; TRP-, $T=-3.5, p=0.001$ ) and after an incorrect NoGo trial (BAL, $T=-2.0, p=0.04$; TRP-, $T=-3.3, p=0.002$ ). No effect of ATD was found on the RT measures.
Subjective measures

Data from the POMS questionnaire, which was complete for all 13 participants, showed that no effect of ATD was found on the subscales for depression $[F(1,11)=0.1, P=\mathrm{NS}]$, anger $[\mathrm{F}(1,11)=0.2, P=\mathrm{NS}]$, fatigue $[\mathrm{F}(1,11)=0.7, P=\mathrm{NS}]$, vigor $[\mathrm{F}(1,11)=0.1, P=\mathrm{NS}]$, and tension $[\mathrm{F}(1,11)=0.0$, $P=\mathrm{NS}]$. A significant main effect of Time was found for vigor $[\mathrm{F}(1,11)=9.8, P<0.05]$. At t0, the participants felt more vigorous (total score of five vigor items is 207; $\mathrm{SE}=17.6$ ) than at $\mathrm{t} 5$ (total score of five vigor items is 224 ; $\mathrm{SE}=13.2$ ).

Data of one subject were missing from the physical complaints list $(n=12)$. No effect of ATD on physical complaints was found $[\mathrm{F}(1,10)=1.8, P=\mathrm{NS}]$. In the BAL condition, the participants had on average a total score of $3.3(\mathrm{SE}=0.9)$ at $\mathrm{t} 0$ and $4.2(\mathrm{SE}=1.0)$ at $\mathrm{t} 5$. In the TRPcondition, the participants had on average a total score of $2.2(\mathrm{SE}=0.8)$ at $\mathrm{t} 0$ and $3.6(\mathrm{SE}=1.0)$ at $\mathrm{t} 5$.

\section{Discussion}

The present study investigated the effect of a transient lowering of 5-HT on performance monitoring and response inhibition related brain activation in 13 healthy male volunteers. In line with previous studies (Asahi et al. 2004; Durston et al. 2002; Garavan et al. 1999, 2002, 2003; Horn et al. 2003; Kelly et al. 2004; Liddle et al. 2001; Menon et al. 2001; Rubia et al. 2003), the present study showed that a widespread network of associated brain regions is involved in response inhibition, including areas in the frontal, parietal, and the temporal cortex. ATD successfully decreased plasma TRP $(-59 \%)$ and the TRP/ $\Sigma$ LNAA ratio $(-77 \%)$ but did not affect mood and task performance. ATD decreased the BOLD response in the dmPFC (BA 8) during performance monitoring and did not change the BOLD response during response inhibition.

Performance monitoring

The present study revealed that ATD modulated the BOLD response in the dmPFC during performance monitoring in a Go/NoGo paradigm in healthy volunteers. The dmPFC was associated with cognitive flexibility. Previous studies showed that the dmPFC (BA 8) is involved in switching behavior during a reversal learning task (Cools et al. 2002; Kringelbach and Rolls 2003; Remijnse et al. 2005) and response uncertainty during a decision-making task (Volz et al. 2004, 2005). Moreover, the medial prefrontal cortex is strongly innervated by the 5 -HT projections from the rostral raphe nuclei (for review, see Hornung 2003). In line with these findings, a previous pharmacological neuroimaging 
study (Evers et al. 2005) reported that ATD modulates the BOLD response in the dmPFC after a final reversal error in a probabilistic reversal learning task in healthy volunteers. These data suggest a role for 5-HT in the functioning of the dmPFC during cognitive flexibility tasks.

To examine the effect of ATD on performance monitoring, we calculated the mean reaction time on the correct response after an error (see Table 2). It is a well-documented finding that participants slow down after an error (post error slowing, first postulated by Rabbitt 1966). It is noteworthy that, although ATD changed the BOLD response in the dmPFC during performance monitoring, we did not find reaction time changes on a correct trial after negative feedback. The performance measures used in this study might not have been sensitive enough to pick up subtle behavioral changes associated with the changed brain activation. Several previous ATD studies also failed to find behavioral effects accompanying the reported effects of ATD on brain activation (Evers et al. 2005; Horacek et al. 2005; Rubia et al. 2005).

In contrast with the present study, which showed that ATD decreased the BOLD response in the dmPFC during performance monitoring, our research group (Evers et al. 2005) showed in a previous study that ATD increased the BOLD response in the $\mathrm{dmPFC}$ after a last reversal error in a probabilistic reversal-learning task. This opposite effect might be related to the different meaning of the negative feedback in the reversal learning and the Go/NoGo task. In the probabilistic reversal learning task, negative feedback after a last reversal error signaled a response error due to a change of the stimulus-response rule, whereas in the Go/NoGo task, negative feedback signaled a response error due to suboptimal performance. Clearly, this hypothesis needs to be tested by future research. Aside from taskrelated differences, there might be another explanation for the contradictory findings. Because ATD studies showed contradictory findings in the past (for example, Rogers et al. 1999 vs Talbot et al. 2005), Talbot et al. (2005) hypothesized that personality characteristics play a decisive role in the effect of ATD on performance and brain activation. Support for this hypothesis is provided by behavioral ATD studies that showed that ATD only affects sensitive individuals. For example, ATD lowers mood in individuals with a positive family history of major depression (see review Riedel et al. 2002) and in individuals that are susceptible to lowered mood or aggression (for review, see Young and Leyton 2002). Moreover, Cools et al. (2005b) showed that ATD modulates the amygdala activation in response to fearful faces as a function of self-reported threat sensitivity, and that ATD impaired motivational guidance of goal-directed behavior on a cued-reinforcement reaction time task as a function of the trait impulsivity (Cools et al. 2005a). Because in our previous and present study participants were not screened and selected on the basis of personality traits, it is possible that unknown personality differences influenced the results. Clearly, this hypothesis needs to be tested by future research. The present study suggests that individual mood changes do not account for these inconsistencies.

Fallgatter et al. (2004) reported that carriers of the short allele variant of a functional length variation in the transcriptional control region of the 5-HT transporter gene, which was associated with an increased risk for depression and anxiety (for review, see Hariri et al. 2006), showed higher amplitude of the error-related negativity compared to carriers of two long alleles. This indicates that a short allele is associated with an enhanced responsiveness of the anterior cingulate cortex (ACC) during error processing. The present study did not show an effect of low 5-HT on ACC activation, but did show decreased activation in the dmPFC after ATD during performance monitoring. The decreased dmPFC activation did not overlap with the taskrelated ACC activation in the BAL condition during performance monitoring. Differences in the experimental design and the 5-HT manipulation might explain the differential effect of low 5-HT on brain activation in these studies. Future studies directly examining the effects of ATD on the ERN (Error-related negativity) might increase our insight in the effect of low 5-HT in dorsomedial frontal regions during performance monitoring.

Response inhibition

The present study did not show that ATD modulated the BOLD response in the right inferior frontal cortex, as the study by Rubia et al. (2005) reported. This might be due to task- and design-related differences in the Go/NoGo tasks that were used. First, the present study used a more difficult Go/NoGo task. The participant had to respond faster due to a predefined time range and, instead of different symbols, the same symbols were used for Gos and NoGos. Due to these differences participants responded faster $(375 \mathrm{~ms}$ vs $459 \mathrm{~ms}$ ) and made more errors ( $70 \%$ vs $98 \%$ of the NoGo trials were successful) in the present study as compared with Rubia's study. Second, performance feedback was given during the task used in the present study. Third, in the study of Rubia et al. both females and males were tested, while in our study only males were used. Previous studies showed that females respond differently to ATD than males do. Booij et al. (2002) showed that total and free plasma TRP decreased more in females than in males after ATD. Harmer et al. (2003) showed that tryptophan depletion decreased recognition of fear in female, but not in male, volunteers. At the moment, the extent to which the effect of ATD on the BOLD response during cognitive flexibility tasks differs between males and females remains unclear. 
The lack of effect of ATD on performance is in agreement with studies that did not find behavioral effects of ATD on response inhibition (Clark et al. 2005; Cools et al. 2005a, Le Marquand et al. 1998, 1999; Rubia et al. 2005). These studies used a Go/NoGo task or a stop signal task to measure response inhibition. In contrast, a study by Walderhaug et al. (2002) reported that ATD increased an impulsive response style on a continuous performance task (CPT) in healthy volunteers. An increase in impulsive response style on the CPT indicates that subjects responded more often to correct stimuli and to catch trials. Because impaired response inhibition on a Go/NoGo or a Stop Signal Task and an impulsive response style on a CPT task reflect a different impairment, it is possible that ATD affects these measures differently.

\section{Conclusions}

The present study showed that ATD modulated the BOLD response during performance monitoring, while leaving performance unchanged. This is in agreement with other studies that showed that 5 -HT is implicated in cognitive flexibility. Because ATD studies have revealed inconsistent effects of ATD on performance and on brain activation, it was hypothesized that the effect of ATD might depend on gender and personality characteristics. Clearly, more research is needed to unravel the effects of low 5-HT on cognitive flexibility.

Acknowledgements This work was supported by a TOP grant (No. 912-02-050) from ZonMW-NWO. This study complies with the Dutch laws for human research and was approved by the Medical Ethics Committee of the Maastricht University Hospital.

\section{References}

Anderson IM, Richell RA, Bradshaw CM (2003) The effects of acute tryptophan depletion on probabilistic choice. J Psychopharmacol 17(1):3-7

Asahi SOY, Okada G, Yamawaki S, Yokota N (2004) Negative correlation between right prefrontal activity during response inhibition and impulsiveness: an fMRI study. Eur Arch Psychiatry Clin Neurosci 254:245-251

Beats BC, Sahakian BJ, Levy R (1996) Cognitive performance in tests sensitive to frontal dysfunction in the elderly depressed. Psychol Med 26:591-603

Biggio G, Fadda F, Fanni P, Tagliamonte A, Gessa G (1974) Rapid depletion of serum tryptophan, brain tryptophan, serotonin and 5 hydroxyindolacetic by a tryptophan-free diet. Life Sci 14: 1321-1329

Booij L, Van der Does W, Benkelfat C, Bremner JD, Cowen PJ, Fava M, Gillin C, Leyton M, Moore P, Smith KA, Van der Kloot WA (2002) Predictors of mood response to acute tryptophan depletion. A reanalysis. Neuropsychopharmacology 27(5):852-861

Bremner JD, Innis RB, Salomon RM, Staib LH, Ng CK, Miller HL, Bronen RA, Krystal JH, Duncan J, Rich D, Price LH, Malison R, Dey H, Soufer R, Charney DS (1997) Positron emission tomography measurement of cerebral metabolic correlates of tryptophan depletion-induced depressive relapse. Arch Gen Psychiatry 54(4):364-374

Clark L, Roiser JP, Cools R, Rubinsztein DC, Sahakian BJ, Robbins TW (2005) Stop signal response inhibition is not modulated by tryptophan depletion or the serotonin transporter polymorphism in healthy volunteers: implications of the 5-HT theory of impulsivity. Psychopharmacology (Berl) 182(4):570-578

Cools R, Clark L, Owen AM, Robbins TW (2002) Defining the neural mechanisms of probabilistic reversal learning using eventrelated functional magnetic resonance imaging. J Neurosci 22 (11):4563-4567

Cools R, Blackwell A, Clark L, Menzies L, Cox S, Robbins TW (2005a) Tryptophan depletion disrupts the motivational guidance of goal-directed behavior as a function of trait impulsivity. Neuropsychopharmacology 30(7):1362-1373

Cools R, Calder AJ, Lawrence AD, Clark L, Bullmore E, Robbins TW (2005b) Individual differences in threat sensitivity predict serotonergic modulation of amygdala response to fearful faces. Psychopharmacology (Berl) 180(4):670-679

Crean J, Richards JB, de Wit H (2002) Effect of tryptophan depletion on impulsive behavior in men with or without a family of history of alcoholism. Behav Brain Res 136:349-357

Durston S, Thomas KM, Worden, MS, Yang Y, Casey BJ (2002) The effect of preceding context in inhibition: an event-related fMRI study. Neuroimage 16:449-453

Elliott R, Sahakian BJ, Herrod JJ, Robbins TW, Paykel ES (1997) Abnormal response to negative feedback in unipolar depression: evidence for diagnosis specific impairment. J Neurol Neurosurg Psychiatry 63:74-82

Evers EA, Cools R, Clark L, van der Veen FM, Jolles J, Sahakian BJ, Robbins TW (2005) Serotonergic modulation of prefrontal cortex during negative feedback in probabilistic reversal learning. Neuropsychopharmacology 30(6):1138-1147

Fadda F (2000) Tryptophan-free diets: a physiological tool to study brain serotonin function. News Physiol Sci 15:260-264

Fallgatter AJ, Merrmann MJ, Roemmler J, Ehlis AC, Wagener A, Heidrich A, Ortega G, Zeng Y, Lesch KP (2004) Allelic variation of serotonin transporter function modulates the brain electrical response for error processing. Neuropsychopharmacology 29 (8): $1506-1511$

Garavan H, Ross TJ, Stein EA (1999) Right hemispheric dominance of inhibitory control: an event-related functional MRI study. Proc Natl Acad Sci U S A 96(14):8301-8306

Garavan H, Ross TJ, Murphy K, Roche RAP, Stein EA (2002) Dissociable executive functions in the dynamic control of behavior: inhibition, error detection, and correction. Neuroimage 17:1820-1829

Garavan H, Ross TJ, Kaufman J, Stein EA (2003) A midline dissociation between error-processing and response-conflict monitoring. Neuroimage 20:1132-1139

Hariri AR, Drabant EM, Weinberger DR (2006) Imaging genetics: perspectives from studies of genetically driven variation in serotonin function and corticolimbic affective processing. Biol Psychiatry (in press)

Harmer CJ, Rogers RD, Tunbridge E, Cowen PJ, Goodwin GM (2003) Tryptophan depletion decreases the recognition of fear in female volunteers. Psychopharmacology (Berl) 167(4):411-417

Harrison AA, Everitt BJ, Robbins TW (1997) Central 5-HT depletion enhances impulsive responding without affecting the accuracy of attentional performance: interactions with dopaminergic mechanisms. Psychopharmacology (Berl) 133(4):329-342

Harrison AA, Everitt BJ, Robbins TW (1999) Central serotonin depletion impairs both the acquisition and performance of a symmetrically reinforced go/no-go conditional visual discrimination. Behav Brain Res 100(1-2):99-112 
Horacek J, Zavesicka L, Tintera J, Dockery C, Platilova V, Kopecek M, Spaniel F, Bubenikova V, Hoschl C (2005) The effect of tryptophan depletion on brain activation measured by fMRI during the Stroop test in healthy volunteers. Physiol Res 54

Horn N, Dolan M, Elliott R, Deakin JFW, Woodruff PWR (2003) Response inhibition and impulsivity: an fMRI study. Neuropsychologia 41:1959-1966

Hornung J (2003) The human raphe nuclei and the serotonergic system. J Chem Neuroanat 26:331-343

Kaiser S, Unger J, Kiefer M, Markela J, Mundt C, Weisbrod M (2003) Executive control deficit in depression: event-related potentials in a Go/NoGo task. Psychiatry Res 122:169-184

Kelly AMC, Hester R, Murphy K, Javitt DC, Foxe JJ, Garavan H (2004) Prefrontal-subcortical dissociation underlying inhibitory control revealed by event-related fMRI. Eur J Neurosci 19: 3105-3112

Kringelbach ML, Rolls ET (2003) Neural correlates of rapid reversal learning in a simple model of human social interaction. Neuroimage 20:1371-1383

LeMarquand DG, Pihl RO, Young SN, Tremblay RE, Seguin JR, Palmour RM, Benkelfat C (1998) Tryptophan depletion, executive functions, and disinhibition in aggressive, adolescent males. Neuropsychopharmacology 19(4):333-341

LeMarquand DG, Benkelfat C, Pihl RO, Palmour RM, Young SN (1999) Behavioral disinhibition induced by tryptophan depletion in nonalcoholic young men with multigenerational family histories of paternal alcoholism. Am J Psychiatry 156(11): 1771-1779

Liddle PF, Kiehl KA, Smith AM (2001) Event-related fMRI study of response inhibition. Hum Brain Mapp 12:100-109

McNair DM, Lorr DM, Droppelman LF (1988) Manual for the profile of mood states. Educational and Industrial Testing Service, San Diego, CA

Menon V, Adleman NE, White CD, Glover GH, Reass AL (2001) Error-related brain activation during a Go/NoGo response inhibition task. Hum Brain Mapp 12:131-143

Morris JS, Smith KA, Cowen PJ, Friston KJ, Dolan RJ (1999) Covariation of activity in habenula and dorsal raphe nuclei following tryptophan depletion. Neuroimage 10:163-172

Murphy FC, Michael A, Robbins TW, Sahakian BJ (2003) Neuropsychological impairment in patients with major depressive disorder: the effects of feedback on task performance. Psychol Med 33(3):455-467

Nishizawa S, Benkelfat C, Young SN, Leyton M, Mzengeza S, De Montigny C, Blier P, Diksic M (1997) Differences between males and females in rates of serotonin synthesis in human brain. Proc Natl Acad Sci U S A 94:5308-5313

Park SB, McShane RH, Young AH, Sahakian BJ, Robbins TW, Cowen PJ (1994) Tryptophan depletion in normal volunteers produces selective impairments in learning and memory. Neuropharmacology 33(3-4):575-588

Psychological Software Tools (2002) E-Prime. http://www.pstnet.com

Rabitt PMA (1966) Errors and error correction in choice reaction tasks. J Exp Psychol 71:264-272

Remijnse P, Nielen MM, Uylings HB, Veltman DJ (2005) Neural correlates of a reversal learning task with an affectively neutral baseline: an event-related fMRI study. Neuroimage 26(2):609-618

Riedel WJ, Klaassen T, Deutz NEP, van Someren A, van Praag HM (1999) Tryptophan depletion in normal volunteers produces selective impairment in memory consolidation. Psychopharmacology 141:362-369

Riedel W, Klaassen T, Schmitt JA (2002) Tryptophan, mood, and cognitive function. Brain Behav Immun 16(5):581-589
Risch S, Nemeroff CB (1992) Neurochemical alterations of serotonergic neuronal systems in depression. J Clin Psychiatry 53(Suppl):3-7

Robbins T (2005) Chemistry of the mind: neurochemical modulation of prefrontal cortical function. J Comp Neurol 493(1):140-146

Rogers R, Blackhaw AJ, Middleton HC, Matthews K, Hawtin H, Crowley C, Hopwood A, Wallace C, Deakin JFW, Sahakian BJ, Robbins TW (1999) Tryptophan depletion impairs stimulusreward learning while methylphenidate disrupts attentional control in healthy young adults: implications for the monoaminergic basis of impulsive behaviour. Psychopharmacology (Berl) 146:482-491

Rogers R, Tunbridge EM, Bhagwagar Z, Drevets WC, Sahakian BJ, Carter CS (2003) Tryptophan depletion alters decision-making of healthy volunteers through altered processing of reward cues. Neuropsychopharmacology 28(1):153-162

Rubia K, Smith AB, Brammer MJ, Taylor E (2003) Right inferior prefrontal cortex mediates response inhibition while mesial prefrontal cortex is responsible for error detection. Neuroimage 20:351-358

Rubia K, Lee F, Cleare AJ, Tunstall N, Fu CHY, Brammer M, McGuire P (2005) Tryptophan depletion reduces right inferior prefrontal activation during response inhibition in fast, eventrelated fMRI. Psychopharmacology (Berl) 179(4):791-803

Smith KA, Morris JS, Friston KJ, Cowen PJ, Dolan RJ (1999) Brain mechanisms associated with depressive relapse and associated cognitive impairment following acute tryptophan depletion. $\mathrm{Br} \mathrm{J}$ Psychiatry 174:525-529

Talbot P, Watson DR, Barrett SL, Cooper SJ (2005) Rapid tryptophan depletion improves decision-making cognition in healthy humans without affecting reversal learning or set shifting. Neuropsychopharmacology (in press)

Talbot PS, Cooper SJ (2006) Anterior cingulate and subgenual prefrontal blood flow changes following tryptophan depletion in healthy males. Neuropsychopharmacology (in press)

Van der Veen FM, Evers EA, van Deursen JA, Deutz NE, Backes WH, Schmitt JA (2006) Acute tryptophan depletion reduces activation in the right hippocampus during encoding in an episodic memory task. Neuroimage (in press)

Van Eijk HM, Rooyakkers DR, Deutz NE (1993) Rapid routine in amino acids in plasma by high-performance liquid chromatography with a $2-3$ microns spherisorb ODS 11 column. J Chromatogr 620:143-148

Volz K, Schubotz RI, von Cramon DY (2004) Why am I unsure? Internal and external attributions of uncertainty dissociated by fMRI. Neuroimage 21(3):848-857

Volz K, Schubotz RI, von Cramon DY (2005) Variants of uncertainty in decision making and their neural correlates. Brain Res Bull 67 (5):403-412

Walderhaug E, Lunde H, Nordvik JE, Landro NI, Refsum H, Magnusson A (2002) Lowering of serotonin by rapid tryptophan depletion increases impulsiveness in normal individuals. Psychopharmacology (Berl) 164:385-391

Williams WA, Shoaf SE, Hommer D, Rawlings R, Linnoila M (1999) Effects of acute tryptophan depletion on plasma and cerebrospinal fluid tryptophan and 5-hydroxyindoleacetic acid in normal volunteers. J Neurochem 72:1641-1647

Winstanley CA, Theobald DEH, Dalley JW, Glennon JC, Robbins TW (2004) 5-HT2a and 5-HT2c receptor antagonists have opposing effects on a measure of impulsivity: interactions with global 5-HT depletion. Psychopharmacology (Berl) 2004176 (3-4):376-385

Young SN, Leyton M (2002) The role of serotonin in human mood and social interaction. Insight from altered tryptophan levels. Pharmacol Biochem Behav 71(4):857-865 